\title{
External Auditor Role in Auditing the Extent of Jordanian Industrial Public Shareholding Companies Compliance in Disclosing about Sustainability Reports Dimensions
}

\author{
Sufyan Salameh Jubarah ${ }^{1}$ \\ ${ }^{1}$ Assistant Accounting Professor, Irbid National University, Irbid, Jordan \\ Correspondence: Sufyan Salameh Jubarah, Assistant Accounting Professor, Irbid National University, Irbid, \\ Jordan.
}

Received: May 3, 2018

Accepted: May 22, 2018

Online Published: May 28, 2018

doi:10.5539/ijef.v10n6p193

URL: https://doi.org/10.5539/ijef.v10n6p193

\begin{abstract}
This study aimed to determine the role of the external auditor in auditing the extent of compliance of Jordanian industrial public shareholding companies in disclosing the dimensions of the sustainability reports. To achieve this study goal, the researcher used the $t$-test for binary comparisons in hypothesis testing. This study population consisted audit offices operate in Jordan, which amount is 82 registered and practicing offices in which 400 registered and practicing auditors work. The study sample was selected randomly from the external auditors in these offices and it consisted of 200 respondents. The study reached to there is a role for the external auditor in auditing the extent of compliance of Jordanian industrial public shareholding companies in disclosing the environmental, economic, and social dimensions. However, the level of this role in disclosing of social dimension was high. The study recommended that the external auditors should verify that companies are committed to publish information about extent of including of the environment in their vision or mission or objectives. The study also recommends confirmation of the auditor's obligation to ensure commitment of the companies in stating the environmental effects when taking investment decisions.
\end{abstract}

Keywords: external auditor, audit, Jordanian industrial public shareholding companies, disclosure of the dimensions of the sustainability reports

\section{Introduction}

The world is witnessing noticeable and fast-growing development Started from the years ago till now adays. In addition to the fierce competition between the global and local companies for obtaining the highest market share through attraction of the largest possible number of investors via the disclosures which these companies provide in their financial reports about their current positions or future plans. Competition between these companies is also containing disclosures subject, so they started to strive to present more accurate and transparent disclosures, such that, these disclosures extended beyond the scope of the foundation, and they started to disclose the extent of their positive contributions to the environment, economy, and society. Hence, so-called sustainability reports emerged, which are reports through which the companies seek to notify the concerned and interested parties about the accomplishments and policies of the companies, whether external and internal, and the future goals that relate to the issues concerned with sustainability and social responsibility. In fact, the process of preparing the sustainability reports accurately and transparently are constitutes a fundamental theme in the field of institutional sustainability. Hence, the companies which present sustainability reports are companies that always seek to develop their reports, through giving the information, that constitutes relative importance for them, and for all related parties in these reports. Because of interest increasing in the service, which is provided by external auditing profession, through performing testing of the reports, and its meeting to the needs of the financial data user, made the auditing profession a contemporary profession for the contemporary economy, in which the decision taker became depending on, and asking for, highly-reliable data that are audited by the external auditor faithfully and impartially.

\subsection{Study Problem}

The research problem lies in studying the role of the external auditor in auditing the extent of compliance of the Jordanian public shareholding industrial companies in disclosing about the dimensions of the sustainability 
reports from the viewpoint of the external auditor,as auditing the extent of commitment of these companies to disclosure of the dimensions of the sustainability reports faces difficulties, problems in compliance, and adaptability with the international environmental accounting standards in this field, These disclosures did not yet reach to the desired level and they require more attention and study, especially Jordan witnesses economic openness, technological development, intensification of competition, and the large size of the industrial companies which have impacts on the environment, economy, and society. Therefore, the research problem is represented in answering the following questions:

First Question: What is the level of the external auditor role in auditing the extent of compliance of the Jordanian industrial public shareholding companies with disclosing the environmental dimension?

Second Question: What is the level of the external auditor role in auditing the extent of compliance of the Jordanian industrial public shareholding companies with disclosing the economical dimension?

Third Question: What is the level of the external auditor role in auditing the extent of compliance of the Jordanian industrial public shareholding companies with disclosing the social dimension?

\subsection{Study Objectives}

The main objective of the study is identifying the role of the external auditor in auditing the extent of compliance of Jordanian industrial public shareholding companies in disclosing the dimensions of the sustainability reports, represented in the environmental, economical, and social dimensions.

\subsection{Study Importance}

Importance of the study comes out from the interest growth in the environment recently, and the irresponsible assaults on the environment and their impacts on the society, which pushed numerous international institutions in numerous forum to ask the companies to present more information accurately and transparently about their activities and their impacts on the environment and society, and about the extent of contribution of these companies in creating ideal environment and society, which, in turn, reflects in sustainable society, economy, and environment, and, in turn, in the need for a neutral party to perform checking of these reports and to disclose them.

\subsection{Study Hypotheses}

First Hypothesis: The external auditor has no role in auditing the extent of compliance of Jordanian industrial public shareholding companies with disclosing the environmental dimension.

Second Hypothesis: The external auditor has no role in auditing the extent of compliance of the Jordanian industrial public shareholding companies with disclosing the economical dimension.

Third Hypothesis: The external auditor has no role in auditing the extent of compliance of the Jordanian industrial public shareholding companies with disclosing the social dimension?

\section{Study Approach}

This study is considered as one of the field studies in which the analytical descriptive approach was followed for the purpose of determining the role of external auditor in auditing the extent of compliance of these companies with disclosing the dimensions of sustainability reports.

\subsection{Study Population}

The study population consisted of the audit offices operating in Jordan, which amount to 82 registered and practicing offices in which 400 registered and practicing auditors work according to the 2017 annual report of the Jordanian Accounts Auditors Society. The study sample, however, was selected from the auditors working in these offices, where 200 questionnaire forms were distributed to the registered and practicing auditors in the offices included in the study. These questionnaire forms were all approved in the statistical analysis.

\subsection{Data Collection Methods}

In this study, two types of information sources were relied upon, which are primary and secondary sources, as follows:

\subsubsection{Primary Data}

In this study, the primary data are those data which were obtained from a questionnaire specific to this study.

\subsubsection{Secondary Data}

In this study, the secondary data are those data which the researcher utilized and obtained from library and from 
literature review of previous studies to develop scientific basics and theoretical framework for this study, like books and scientific sources researching in accounting, especially those which research in auditing, accounting, and disclosure on sustainability reports

\subsection{The Data Collection Tool}

The researcher designed a questionnaire that included all the study variables and covered the hypotheses on which this study leaned, using evaluative statements to determine importance of the responses of the study sample.

\subsubsection{Validity and Reliability of the Tool}

The researcher presented the questionnaire to some faculty members in Jordanian universities specialized in the fields of accounting and statistics to judge its validity as a data collection tool. After receiving their comments, the researcher performed some of modifications suggested by them. Afterwards, the questionnaire was distributed to auditors working in audit offices operating in Jordan.

The researcher used the five-point Likert scale in which the following weight (number of points) was assigned to each of the levels of agreement of the respondents on the questionnaire items: strongly agree (5 points), agree (4 points), agree to some extent ( 3 points), disagree ( 2 points), and strongly disagree ( 1 point). To confirm reliability of the questionnaire as a tool for collection of necessary data for the present study, the questionnaire was subjected to reliability analysis using Cronbach's Alpha coefficient as a criterion. This questionnaire had a Cronbach's Alpha coefficient of 0.96 , which is a value that indicates very high instrument reliability.

\subsubsection{Methods of Statistical Analysis of the Data}

The Statistical Package for Social Sciences (SPSS) was employed in calculating descriptive statistics for the research data, conducting frequency, distribution analysis, and running ( $T$-Test) for dual comparisons.

\section{Previous Studies}

Hasan (2016); the study conducted to test, and evaluate, the sustainability reports as a new challenge for the external auditing profession. The study found that there is a limitation (deficit) in setting fixed criteria for the external audit to confirm about the sustainability reports.

Study of Barman (2016) concluded that there are problems, and challenges that appear as a result of growth of the small and medium industries that need immediate attention, and sustainable management and which affect the environment, thus leading to reduction of the spatial bases of the varied macro and micro ecological systems.

Airoot (2015) carried out a study whose results indicated that the commercial banks confine in their disclosure process in the sustainability reports to the economical and social dimensions, avoiding and marginalizing the environmental dimension and its effect on the market value

Study of Bashatwah (2014) showed (i) presence of significant influence of disclosing the economical and social aspects on the continuity index; (ii) lack of such influence in the case of disclosure of the environmental dimension; and (iii) presence of significant influence of disclosure on the three dimensions, with varying effects, on the continuity index.

Study of Al-Armooti (2013) found presence of effect, represented in the form of presence of statistical performance indicator for the three sustainable development dimensions since it has the big effect on the disclosure element in the financial reports of the shareholding industrial companies.

Despite that many of the aforementioned studies addressed feasibility and importance of sustainability accounting and its effects on environmental and social surrounding, the current study addresses the concept of sustainability accounting from another practical perspective in which it integrates the concepts of disclosure, auditing, sustainability, and accounting affairs together. In addition to that, this study sheds the light on a process that is counted as a very important part in the sustainability reports, which is auditing.

\section{Theoretical Framework}

In perception at sustainability concept, and its concern with the environmental green resources, and social resources, resulted in concentration of studies in recent times on scientific and practical dimensions that are almost limited, most of which is restricted to comprehensiveness of this concept and the aspects that are managed for its application without holistic concentration on the economical dimensions, and the criteria and foundations falling below them, that contribute to sustaining and developing the sustainability plans.

It is worth mentioning, that accounting has an important role to play in the context of tracking environmental and social resources in local and global companies, whether shareholding or industrial, and whatever their type is. 
This role is concerned with tracking cost specific to any company, whether revenues or imports, which is in specific known as the process of sustainability accounting.

This sort of the accounting is considered as dynamic, sequential process under which is listed every environmental, social, and economical requirement, to be studied as a benefit, and, in consequence, actual cost that listed on the costs list of every company. In calculation of the financial feasibility of the costs of the companies, specialized external auditors prepare special accounting reports for disclosing the feasibility of sustainability in first place, and accounting and institutional sustainability behavior in second place.Hence, importance of the role of the external accounts in preparing sustainability reports comes out. Not only this, but also their effective role in disclosing the progress and feasibility of sustainability in the company in which accounting audit is implemented, considering that every cost represents a benefit, either environmental or economical or social benefit. From this point, this study came to identify the role of the external auditors in disclosing the behavior, and feasibility of sustainability through its reports prepared in the industrial companies.

\subsection{Nature of External Accounts Auditing}

The auditing process is defined as a process organized within a plan characterized with objectivity, such that it guarantees performing this task with all accuracy, and comprehensiveness, where the individuals who do it as qualified individuals, namely, Auditors. There are several conditions and features/properties, that must be available in the person who performs the process of auditing, such that not anyone can practice it unless she/he enjoys these conditions. The auditing process is not confined to being an accounting process but it is pure technical process, on which are built the financial opinions, experiences, and consultations (Jumaah, 2009).

The external auditing process of the sustainability reports includes three main dimensions: environmental, social, and economical dimensions. Based on that, each dimension has main auditing nature, and objective, which the external auditor seeks to achieve, and whose comprehensiveness was stated by the International Standard for the Principles of Social Responsibility (ISO 26000 Sustainability Standards) as it included seven main items that are taken into consideration when auditing the sustainability report, which are organizational governance, human rights, work practices, environment, fair recruitment, consumer' $\quad \mathrm{s}$ issues, community partnership and development. Therefore, auditing includes what follows (Hasan, 2016):

\subsubsection{Environmental Auditing}

This auditing is based on examining costs and revenues of the factors related to environmental issue.

\subsubsection{Social Auditing}

This auditing is based on studying social factors between the organization and stakeholders such that includes investigation of :supply chain, customers' protection, employees' practices, and community benefits.

\subsubsection{Economical Auditing}

This auditing encompasses checking and reviewing financial matters of revenues and returns resulting from the inputs, outputs, and processes of the foundation.

\subsection{Sustainability Accounting and Sustainable Development: (Concept, and Importance)}

The concept of sustainability accounting stands basically on the extent of the actual realization of the social, economical, and environmental resources, that are available in any surrounding area, where each element of which constitutes a benefit that returns mutual benefit. From an accounting perspective, the benefit is a real cost that is counted within data and whose feasibility is measured in statistical studies. This benefit can be economical, or environmental, or social benefit.Therefore, from this standpoint, the sustainability accounting process is a comprehensive, and technical process, that enables the stakeholders to audit the economical and environmental activities, which they perform, and, in consequence, auditing the decisions related to the costs, and benefits, that influence the income and outcomes of the company later. The concept of sustainability, however, in general stands on limiting degradation of the renewable environmental resources and ecological systems in any way. This naturally includes the human resources and quality of life which be lived by inhabitants of the earth. However, in specific, the sustainability concept addressed two directions, the first is: an environmental direction while the second is: an economical direction (Abo Zanat, 2005). Sustainable development is defined as: process of set of basic changes in a certain society with the goal of empowering that society with the capability for continuous of self-change at a rate that warrants improvement in the quality of life for all its individuals, that is, increasing the ability of the society to respond to the growing basic needs of its members in the way that guarantees increasing the degrees of satisfaction of those needs by means of continuous rationalization of exploitation of the available economical resources (Al-Khazaali, 2005). 
The importance of development, environmentally, lies in reducing the environmental pressures and directing them towards a versed administrative direction to keep them and exploit them without human or environmental waste. As to the human form that falls within this set, there are several goals that sustainable development seeks to achieve and set/establish/confirm through the development, which are summarized in achieving equality in the social gender; raising the levels of education, health, and well-being; providing new job opportunities; creating knowledge economical environment; and providing residential and health care. What enriches all that is development, which includes the third path/track, i.e., the economy path. Here, the stakeholders work on proceeding in stopping the suffer of hunger, poverty, vagrancy, and asylum; preparing an economic structure of biological origin; creating a balance between the production and consumption styles; providing vital and effective investment environments in the shade of globalization; managing some difficult resources in a way whereby they are reused; and creating job opportunities to reduce unemployment (Kolk \& Perego, 2008).

\subsubsection{The Sustainability Reports (Concept and Importance)}

The sustainability reports are defined by their usual name which it acquired since its emergence. However, there are companies that prepare these reports under the label of environmental or social reports. Within this context, Kotaysghat (2010) pointed to comprehensiveness of listing these reports under the name of sustainability reports for what this naming has of comprehensiveness of the three aspects; environmental, social, and cultural aspects, and not being restricted to their being social or environmental reports. Concentration on sustainability reports term emerged in light of advancement of science in the business environment economically, socially, and environmentally, where the main focus headed towards the organizational performance which flows into structuring and activation of elements that serve these three aspects in an integrated manner. According to this process and what its implementation requires, these reports reflect the behaviors which the industrial and other companies make in addressing the human, material, and immaterial data in them together eventually affecting all of the environment, economy, and society (Abdol Monim \& Al-Ajloani, 2013).

The sustainability reports have three dimensions, as the sustainability report represents the indicator of measurement of social, economical, and environmental performance of the companies. Moreover, it represents the facet of disclosure of outcomes, or results of this performance for the purpose of evaluation of contribution of the industrial companies to achievement of the sustainable development plans. This disclosure includes social outputs, environmental resource management, and the economical feasibility and its revenues (Abo Zer, 2011).

As endorsed by the (World Business Council for Sustainable Development) on importance of preparation of the sustainability reports, it briefed that importance including enduring survival of the organizations through continuity of their efficient and effective performance in terms of the three integrated levels, attraction of the competencies with minds and experience, attraction of the studied investments and contributions, creating a creative environment, creating the institutional integrity and transparency, and framing the fair institutional management principles

\subsubsection{Disclosure in the Sustainability Reports}

The sustainability reports express the performance of the companies in the three domains; the economical, environmental, and social domains, in addition to the role which the stakeholders play and the goals expected to be achieved in the future (Bebbington, 2014). For this reason, these reports must be prepared in an objective and honest disclosure. It is worth mentioning that what we mean by disclosure from the perspective of the sustainability accounting is a standard disclosure in which the indicators of the environmental, economical, and social performance are translated into material/financial values that are calculated besides measuring the percentage of the probable standard deviations in them. To reinforce the disclosure element in the sustainability reports, there are several factors that must be considered (Burritt \& Schaltegger, 2010):

1) Inclusion of the sustainability reports of the aforementioned three aspects and the stakeholders.

2) Depicting the performance diversity and so on which the stakeholders enjoy. In this way, investment and communication channels between the different stakeholders are developed, and, in turn, interest of the company is obtained.

3) Addressing all the three aspects in a balanced and fair away.

4) Establishing a structural and strategic link between the administrations of the institutions and the business owners.

5) Choosing the suitable time for disclosure of the results of the sustainability reports, be them yearly or governmental or others, as this factor is considered as a necessary business imperative that must be adopted to avoid the losses of the competitive variables and investment. 
6) Taking into consideration that these reports are not confined to being a tool of communication between the stakeholders and the establishment but that it is an organizational tool that contributes to achievement of the goals of the strategic plan of the company and setting the future goals, in addition to its contribution as an effective means in risk management.

Of the main means that work on reinforcing the disclosure element in preparation of the sustainability reports are the following (Orij, 2010):

1) Involving the stakeholders, where they determine the information and target goals of these reports. According to the scientific initiative of the reports, this is what is looked at in the first stage of preparation of the sustainability reports, that is, the (Why-Stage).

2) Realization of the work frames, where the involved persons and the stakeholders work on specifying the scope of coverage as regards the information needed to be disclosed from the reports.

3) Benchmarking, where the report of the establishment is disclosed within the reports of the rival establishments, which leads to guaranteed successful disclosure in its report.

Through activation of these means the standard disclosure mechanism in the sustainability reports is reinforced.

\section{Results of Descriptive Analysis and Testing of Study Hypotheses}

\subsection{Results Related to the First Research Question}

What is the level of the external auditor role in auditing the extent of compliance of Jordanian industrial public shareholding companies with disclosing environmental dimension?

Table 1. The means, standard deviations, and rank for the level of external auditor role in auditing the extent of companies compliance with disclosing environmental dimension listed in descending order

\begin{tabular}{|c|c|c|c|c|c|}
\hline Rank & Item $\#^{1}$ & Item & Mean & S.D ${ }^{2}$ & Item \# \\
\hline 1 & 10 & $\begin{array}{l}\text { Knowledge of the company of the penalties and fine that may be imposed on it } \\
\text { as a result of not implementing its environmental responsibility is ascertained. }\end{array}$ & 3.732 & .8736 & High \\
\hline 2 & 6 & $\begin{array}{l}\text { The auditor confirms determination and classification of the environmental costs } \\
\text { appearing in the financial reports of the company. }\end{array}$ & 3.7120 & .8672 & High \\
\hline 3 & 4 & $\begin{array}{l}\text { The auditor verifies that the environmental costs are shown in the final } \\
\text { calculations represented in the income calculations and the financial position list. }\end{array}$ & 3.620 & .9159 & Medium \\
\hline 4 & 7 & $\begin{array}{l}\text { The auditor confirms publication of information about size of consumption of } \\
\text { natural resources by the company in its annual report. }\end{array}$ & 3.620 & .9957 & Medium \\
\hline 5 & 2 & $\begin{array}{l}\text { There is care to know the extent of compliance of the company with providing } \\
\text { support for the accountants and encouraging them to employ the concept of } \\
\text { sustainable accounting and practicing it in their work. }\end{array}$ & 3.580 & .8507 & Medium \\
\hline 6 & 9 & $\begin{array}{l}\text { The auditor exerts efforts to know the extent of compliance of the company with } \\
\text { controlling the costs of energy consumption and saving it. }\end{array}$ & 3.572 & .9882 & Medium \\
\hline 7 & 3 & $\begin{array}{l}\text { Disclosure of the company of the accounting policies related to the } \\
\text { environmental costs is confirmed. }\end{array}$ & 3.488 & .9662 & Medium \\
\hline 8 & 5 & $\begin{array}{l}\text { The auditor uses her/his skill to know the extent of compliance of the company } \\
\text { in its annual lists with disclosure of the costs related to disposing of any wastes } \\
\text { that harm the environment. }\end{array}$ & 3.480 & .9420 & Medium \\
\hline 9 & 8 & $\begin{array}{l}\text { Compliance of the company with pronouncing the environmental impacts when } \\
\text { taking the investment decisions. }\end{array}$ & 3.408 & .8611 & Medium \\
\hline \multirow[t]{2}{*}{10} & 1 & $\begin{array}{l}\text { Compliance of the company with publishing information about extent of } \\
\text { inclusion of the environment in its vision, mission, and objectives is ensured. }\end{array}$ & 3.276 & .9157 & Medium \\
\hline & & Total & 3.548 & & High \\
\hline
\end{tabular}

${ }^{1}$ Item \#: Number of the item in the respective domain in the questionnaire. ${ }^{2}$ S.D: Standard deviation.

Table 1 shows that the arithmetic average of the level of the role which the external auditor plays in auditing the extent of compliance of the companies with disclosing the environmental dimension as a whole is (3.548), and is (Medium) in degree. This mean expresses this role from the point of view of the sample. The means of the items of this dimension ranged from (3.276 to 3.732), where it discerned that the item of disclosure of the environmental dimension that is most important was Item no. (10), which states that "Knowledge of the company of the penalties and fine that may be imposed on it as a result of not implementing its environmental 
responsibility is ascertained. It ranked first and had a mean score of (3.732), a standard deviation of 0.8736 , and a high degree. It discerned that the least important item of this question from the viewpoint of the study sample is Item no. (1), which states that "Compliance of the company with publishing information about extent of inclusion of the environment in its vision, mission, and objectives is ensured". It ranked last in importance with a mean score of 3.276, standard deviation of 0.9157 , and medium degree of importance. The standard deviations of the items indicate lack of scatter in the answers of the study sample

\subsection{Results Related to the Second Research Question}

What is the level of the external auditor role in auditing the extent of compliance of Jordanian industrial public shareholding companies with disclosing economical dimension?

Table 2. The means, standard deviations, and rank for level of external auditor role in auditing the extent of companies compliance with disclosing economical dimension listed in descending order

\begin{tabular}{|c|c|c|c|c|c|}
\hline Rank & Item $\#^{1}$ & Item & Mean & S.D ${ }^{2}$ & Degree \\
\hline 1 & 20 & $\begin{array}{l}\text { The auditor reviews the extent of compliance of the company with disclosure } \\
\text { of its continuous economical (financial) performance. }\end{array}$ & 3.720 & .9019 & High \\
\hline 2 & 14 & $\begin{array}{l}\text { The auditor ensures ability of the administration of the company to optimally } \\
\text { use the resources available in it. }\end{array}$ & 3.636 & .9216 & Medium \\
\hline 3 & 13 & $\begin{array}{l}\text { Extent of compliance of the company with disclosure of the costs it pays to } \\
\text { support the infrastructures of the national community is reviewed. }\end{array}$ & 3.612 & .9400 & Medium \\
\hline 4 & 16 & $\begin{array}{l}\text { The auditor cares to know the extent to which administration of the company } \\
\text { follows the sound economical principles and foundations to establish a plan } \\
\text { for cost control (elaborate feasibility study) }\end{array}$ & 3.600 & .9060 & Medium \\
\hline 5 & 15 & $\begin{array}{l}\text { The auditor sets criteria to confirm respect of the administration of the } \\
\text { company of the competition rules and not harming the rivals for its interest } \\
\text { (decent competition). }\end{array}$ & 3.584 & .8465 & Medium \\
\hline 6 & 17 & $\begin{array}{l}\text { The auditor cares to know the extent of success which the company achieves } \\
\text { in reducing the cost and improving its economical (financial) position. }\end{array}$ & 3.568 & .8667 & Medium \\
\hline 7 & 19 & $\begin{array}{l}\text { The auditor cares to know the extent of success which the company achieves } \\
\text { in maximizing the profitability. }\end{array}$ & 3.568 & .9804 & Medium \\
\hline 8 & 12 & $\begin{array}{l}\text { Compliance of the administration of the company with disclosure of any risks } \\
\text { which the company may face in the future is confirmed. }\end{array}$ & 3.508 & .9726 & Medium \\
\hline 9 & 11 & $\begin{array}{l}\text { Extent of compliance of the company with disclosure of the costs it pays to } \\
\text { support the infrastructures of the national community is reviewed. }\end{array}$ & 3.488 & .9380 & Medium \\
\hline \multirow[t]{2}{*}{10} & 18 & $\begin{array}{l}\text { The auditor ensures abilities of the company to introduce the new and modern } \\
\text { methods in the work that are due to raise efficiency of the company (efficient } \\
\text { management). }\end{array}$ & 3.487 & .9908 & Medium \\
\hline & & Total & 3.577 & & ligh \\
\hline
\end{tabular}

${ }^{1}$ Item \#: Number of the item in the respective domain in the questionnaire. ${ }^{2}$ S.D: Standard deviation.

Table 2 shows: that the mean of the level of the role which the external auditor plays in auditing the extent of compliance of the companies with disclosing the economical dimension as a whole is (3.577) and is average in degree. This mean expresses this role from the point of view of the sample. The means of the items of this dimension ranged from (3.487 to 3.720), where it discerned that the item of disclosure of the economical dimension that is most important was Item no. (20), which states that "The auditor reviews the extent of compliance of the company with disclosure of its continuous economical (financial) performance." It ranked first with a mean score of (3.720), a standard deviation of (0.9019), and a high degree. It discerned that the least important item of this question from the viewpoint of the study sample is Item (18), which states that "The auditor ensures abilities of the company to introduce the new and modern methods in the work that are due to raise efficiency of the company (efficient management)." It ranked last in importance with a mean score of (3.487), standard deviation of (0.9908), and medium degree of importance. The standard deviations indicate lack of dispersion in the answers of the study sample.

\subsection{Results Related to the Third Research Question}

What is the level of the external auditor role in auditing the extent of compliance of Jordanian industrial public shareholding companies with disclosing social dimension? 
Table 3. The means, standard deviations, and rank for the level of external auditor role in auditing the extent of companies compliance with disclosing social dimension listed in descending order

\begin{tabular}{|c|c|c|c|c|c|}
\hline Rank & Item $\#^{1}$ & Item & Mean & S.D ${ }^{2}$ & Degree \\
\hline 1 & 30 & $\begin{array}{l}\text { The auditor reviews the extent of ability of the company to incur any additional costs } \\
\text { in return for satisfying its social responsibility. }\end{array}$ & 4.160 & .7215 & High \\
\hline 2 & 25 & $\begin{array}{l}\text { The auditor ensures that the administration of the company seeks improve the } \\
\text { material working conditions for its workers. }\end{array}$ & 3.852 & .7010 & High \\
\hline 3 & 28 & $\begin{array}{l}\text { The auditor assures disclosure by the company of the information that contributes to } \\
\text { provision of job opportunities to address unemployment. }\end{array}$ & 3.748 & .8761 & High \\
\hline 4 & 29 & $\begin{array}{l}\text { The auditor ensures disclosure by the company in its published data of the costs it } \\
\text { bears in return for serving the local community. }\end{array}$ & 3.740 & .8486 & High \\
\hline 5 & 21 & $\begin{array}{l}\text { The auditor reviews the bases which the company follows to address its social } \\
\text { responsibility in accounting and its possession of a system that fulfills this purpose. }\end{array}$ & 3.684 & .8100 & High \\
\hline 6 & 26 & $\begin{array}{l}\text { The auditor confirms disclosure by the company of the costs it carries in return of } \\
\text { training the employees and equipping them with the necessary skills. }\end{array}$ & 3.652 & .8232 & Medium \\
\hline 7 & 27 & $\begin{array}{l}\text { The auditor reviews the extent of possession of the company of awards and } \\
\text { discretionary certificates awarded to it on the extent of its abidance with quality and } \\
\text { public safety. }\end{array}$ & 3.636 & .8057 & Medium \\
\hline 8 & 22 & $\begin{array}{l}\text { The auditor ensures the ability of the company to disclose the social costs that } \\
\text { probably lower the future revenues and cash flows. }\end{array}$ & 3.564 & 6984 & Medium \\
\hline 9 & 24 & $\begin{array}{l}\text { The auditor assures well preparation of the salary and wage system by the company } \\
\text { in terms of fairness and that it parallels the paid efforts. }\end{array}$ & 3.540 & .9981 & Medium \\
\hline 10 & 23 & $\begin{array}{l}\text { The auditor focuses on knowing the abilities of the company to disclose in its } \\
\text { financial data the value of donations and financial aids provided for the } \\
\text { organizations and charities. }\end{array}$ & 3.412 & .8765 & Medium \\
\hline
\end{tabular}

${ }^{1}$ Item \#: Number of the item in the respective domain in the questionnaire. ${ }^{2}$ S.D: Standard deviation.

Table 3 shows that the mean of the level of the role which the external auditor plays in auditing the extent of compliance of the companies with disclosing the social dimension as a whole is 3.698 and is high in degree. This mean expresses this role from the point of view of the sample. The means of the items of this dimension ranged from (4.160 to 3.412), where it discerned that the most important item of this dimension from the point of view of the study sample was Item (30), which states that "The auditor reviews the extent of ability of the company to carry any additional The auditor reviews the extent of ability of the company to incur any additional costs in return for satisfying its social responsibility." It ranked first with a mean score of (4.160), a standard deviation of (0.7215), and a high degree. It discerned that the least important item of this dimension from the perspective of the study sample is Item (23), which states that "The auditor focuses on knowing the abilities of the company to disclose in its financial data the value of donations and financial aids provided for the organizations and charities." It ranked last with a mean score of (3.412), standard deviation of (0.8765), and medium degree of importance. The standard deviations of the items indicate lack of scatter in the answers of the study sample.

\section{Results of Testing the Research Hypotheses}

To test the research hypotheses, the one-sample t-test was used for comparisons. The decision rule states that the null hypothesis $\left(\mathrm{H}_{0}\right)$ is rejected and the alternative hypothesis $\left(\mathrm{H}_{\mathrm{A}}\right)$ is accepted if the value of the calculated $t$ is higher than the corresponding tabulated value. Based on this rule, the tests were performed and the results were as illustrated in the following tables.

\subsection{First Hypothesis Test}

The first null hypothesis related to the first hypothesis stated that the external auditor does not have a role in auditing the extent of compliance of the Jordanian industrial public shareholding companies with disclosing the environmental dimension.

Table 4. Results of the one-sample t-test for the first hypothesis

\begin{tabular}{ccccccc}
\hline Sample Size & Mean & S.D $^{1}$ & Calculated $t$ & Tabulated $t$ & Sig. & Decision \\
\hline 250 & 3.548 & .7397 & 75.85 & 1.96 & $0.000^{2}$ & Rejection \\
\hline
\end{tabular}

${ }^{1}$ S.D: Standard deviation. ${ }^{2}$ Statistically significant at the level of significance $(\alpha)$ of 0.05 .

The results of the one-sample $t$-test in Table 4 indicate that the value of the calculated $t$ is (75.85) while the corresponding tabulated value is (1.96). By comparing of the results obtained from testing this hypothesis, the null hypothesis is rejected and the alternative hypothesis is accepted. The alternative hypothesis states that the 
external auditor has a role in auditing the extent of compliance of the Jordanian industrial public shareholding companies with disclosing environmental dimension. Based on the statistical decision rule too if the value of Sig. is equal to (0.000), then the null hypothesis $\left(\mathrm{H}_{01}\right)$ is rejected and the alternative hypothesis $\left(\mathrm{H}_{\mathrm{A1}}\right)$ is accepted. That is, the external auditor has a role in auditing the extent of compliance of the Jordanian industrial public shareholding companies with disclosing the environmental dimension from the point of view of the sample of accounts auditors working in theauditing offices in Jordan.

\subsection{Second Hypothesis Test}

The second null hypothesis related to the first hypothesis stated that the external auditor does not have a role in auditing the extent of compliance of the Jordanian industrial public shareholding companies with disclosing economical dimension.

Table 5. Results of the one-sample t-test for the second hypothesis

\begin{tabular}{ccccccc}
\hline Sample Size & Mean & S.D $^{1}$ & Calculated $t$ & Tabulated $t$ & Sig. & Decision \\
\hline 250 & 3.577 & .8579 & 65.78 & 1.96 & $0.000^{2}$ & Rejection \\
\hline
\end{tabular}

The results of the one-sample $t$-test in Table 5 point out that the value of the calculated $t$ is 65.78 while the respective tabulated value is 1.96 . By comparing of the results obtained from testing this hypothesis, the null hypothesis is rejected and the alternative hypothesis is accepted. The alternative hypothesis states that the external auditor has a role in auditing the extent of compliance of the Jordanian industrial public shareholding companies with disclosing the economical dimension. Based on the statistical decision rule too, if the value of Sig. is equal to (0.000), then the null hypothesis $\left(\mathrm{H}_{02}\right)$ is rejected and the alternative hypothesis $\left(\mathrm{H}_{\mathrm{A} 2}\right)$ is accepted. That is, the external auditor has a role in auditing the extent of compliance of the Jordanian industrial public shareholding companies with disclosing the economical dimension from the point of view of the sample of accounts auditors working in the auditing offices in Jordan.

\subsection{Third Hypothesis Test}

The third null hypothesis related to the third hypothesis stated that the external auditor does not have a role in auditing the extent of compliance of the Jordanian industrial public shareholding companies with disclosing the social dimension.

Table 6. Results of the one-sample t-test for the second hypothesis

\begin{tabular}{ccccccc}
\hline Sample Size & Mean & S.D & Calculated $t$ & Tabulated $t$ & Sig. & Decision \\
\hline 250 & 3.698 & .7002 & 83.52 & 1.96 & $0.000^{2}$ & Rejection \\
\hline & ${ }^{1}$ S.D: Standard deviation. ${ }^{2}$ Statistically significant at the level of significance $(\alpha)$ of 0.05. & & & &
\end{tabular}

The results of the one-sample $t$-test in Table 6 point out that the value of the calculated $t$ is (83.52) while the respective tabulated value is (1.96). By comparing of the results obtained from testing this hypothesis, the null hypothesis is rejected and the alternative hypothesis is accepted. The alternative hypothesis states that the external auditor has a role in auditing the extent of compliance of the Jordanian industrial public shareholding companies with disclosing the social dimension.Based on the statistical decision rule too, if the value of Sig. is equal to 0.000 , then the null hypothesis $\left(\mathrm{H}_{03}\right)$ is rejected and the alternative hypothesis $\left(\mathrm{H}_{\mathrm{A} 3}\right)$ is accepted. That is, the external auditor has a role in auditing the extent of compliance of the Jordanian industrial public shareholding companies with disclosing the social dimension from the point of view of the sample of accounts auditors working in the auditing offices in Jordan.

\section{Discussion of Results}

The results showed what follows:

1) It discerned that there is a role for the external auditor in auditing the extent of compliance of the Jordanian industrial public shareholding companies with disclosing the environmental dimension and that the level of this role was medium from the point of view of the sample of auditors working in the auditing offices in Jordan. It also discerned that the auditor confirms (i) knowledge of the company about the sanctions and fees/fines/??? that may be imposed on it as a result of not implementing its environmental responsibility; (ii) determination and classification of the environmental costs appearing in the financial reports of the company; and (iii) the environmental costs are shown in the final calculations represented in the income calculations and the financial position list. This result differs from the results of the study of Bashatwah (2014) which found no effect for 
disclosure of the environmental aspect. This result also differs from the result of the study of Al-Armooti (2013) which found an effect for the environmental dimension on the disclosure element in the financial reports of the industrial companies.

The researcher explains this result that the costs are looked at as the amount of expenses which the company bears for the purpose of preserving the environment, but from the corporate accounting point of view the environmental costs represent the sums that are spent and which the economic activity does not require. It is usually characterized by that the company does not get benefit or direct economical return in exchange for it as they represent sums that are spent as a result of commitment of the company to some of its environmental responsibilities, optionally or in application of environmental laws and regulations, in addition to the costs of the environmental damage which the company might have inflicted on the society.

2) It appeared that there is a role for the external auditor in auditing the extent of compliance of the Jordanian industrial public shareholding companies with disclosing the economical dimension and that the level of this role was medium from the point of view of the sample of accounts auditors working in the auditing offices in Jordan. It also appeared that the auditor (i) The auditor reviews the extent of compliance of the company with disclosure of its continuous economical (financial) performance; (ii) ensures ability of the administration of the company to optimally use the resources available in it; and (iii) reviews extent of compliance of the company with disclosure of the costs it pays to support the infrastructures of the national community. This result agrees with the result of the study of Ayroot (2015) which found that in the sustainability reports the commercial banks disclose the economical dimension. In addition, this result agrees with the result of the study of Al-Armooti (2013) which found an effect for the economical dimension on the disclosure element in the financial reports of the industrial companies.

The researcher explains this result by that correlation of the economical factors with the economical development and economical performance leads to necessity of providing the adequate protection for the environment so that the environmental resources will not become deficient from meeting the investment needs, on the one hand, and so that no negative impacts will inflict on the human being as the key element in the development process, that will make him incapable of investment and satisfying his future needs, on the other hand.

3) It appeared that there is a role for the external auditor in auditing the extent of compliance of the Jordanian industrial public shareholding companies with disclosing the social dimension and that the level of this role was high from the point of view of the study sample of accounts auditors working in the auditing offices in Jordan. Moreover, it appeared that the auditor (i) reviews the extent of ability of the company to carry any additional costs in return of satisfying its social responsibility; (ii) ensures that the administration of the company seeks improve the material working conditions for its workers; (iii) assures disclosure by the company of the information that contributes to provision of job opportunities to handle/treat unemployment; and (iv) ensures disclosure by the company in its published data of the costs it carries in return of serving the local community. This result agrees with the result of the study of Bashatwah (2014) which found that an effect exists for disclosure of the social aspect.

The researcher explains this result by that the fundamental goal of the social dimension lies in attempting to subdue the social and environmental performance of the company to the theoretical framework of accounting to reach to a specialized accounting system that works on measuring the environmental and social costs and reviewing them and disclosing them in the financial reports and lists to satisfy the needs of the external parties by relying on the new accounting publications and standards that contribute to modification of the accounting system for it to include new calculations that keep pace with the social and environmental developments.

\section{Recommendations}

The researcher recommends what follows:

1) Auditor's confirmation of the compliance of the company with publishing information about extent of inclusion of the environment in its vision, mission, and objectives is ensured.

2) Emphasis on the auditor of the necessity of confirming compliance of the companies with pronouncing the environmental impacts when taking the investment decisions.

3) Assurance by the auditor of abilities of the company to introduce the new and modern methods in the work which are due to raise efficiency of the company.

4) Reliance of the auditor on her/his self abilities to know the extent of compliance of the company with disclosing any risks that it may face in the future. 
5) Focusing by the auditor on knowing the abilities of the company to disclose in its financial data the value of donations and financial aids provided for the charity societies and organizations.

6) Reliance of the auditor on her/his abilities to know the ability of the company to disclose the social costs that probably lower the future revenues and cash flows.

\section{References}

Abdol, M. O., \& Al-Ajloani, A. T. (2013). The sustainability reports: The real embodiment of corporate governance in the companies: A field study from the viewpoint of the Jordanian external accounts auditors. Anbar University Journal of the Economic and Administrative Sciences, 5(10), 153-180.

Abo Zanat, M. (2005). Measurement of the sustainable development and its standards. Azaytonah for Scientific Studies and Research, 1, 66-87.

Abo Zer, A. I. (2011). Financial disclosure for sustainability: Reality and horizons. A research submitted to the $9^{\text {th }}$ International Professional Scientific Conference, the Jordanian Legal Accountants Society, titled: Developing the structure of the financial reports in the aftermath of the world financial crisis, 28-29 September, Amman, Jordan.

Al-Armooti, A. (2013). Effect of sustainability accounting on the financial disclosure reports in the Jordanian shareholding industrial companies in Amman Bourse. Master's thesis, Middle East University, Amman, Jordan.

Al-Khazaali, A. H. (2005). Suatainable development: An Islamic vision. Journal of Strategic Research and Studies, 1(4), 119-133.

Assaffar, H. R. (2006). Accounting for the sustainable environment. A research submitted to the $6^{\text {th }}$ Annual Scientific Conference, titled: Business ethics and the knowledge society, Azaytonah University, Faculty of Economics and Administrative Sciences, Amman, Jordan.

Ayroot, R. M. (2015). Effect of level of disclosure of the sustainability reports on the market values of the Jordanian commercial banks. Doctoral thesis, International Islamic Sciences University, Amman, Jordan.

Barman, P., \& Saikia, K. (2016). Environmental accounting and sustainable development: A study in some small and medium enterprises industrial estates of Assam, India. Clarion: International Multidisciplinary Journal, 5(2), 4-9. https://doi.org/10.5958/2277-937X.2016.00023.X

Bashatwah, A. Z. M. (2014). Effect of financial disclosure of the sustainability reports on ability of the banks to continue: A field study of the Jordanian banks. Master's thesis, Jadara University, Irbid, Jordan.

Bebbington, J., Unerman, J., \& O'Dwyer, B. (2014). Sustainability accounting and accountability. Routledge.

Burritt, R. L., \& Schaltegger, S. (2010). Sustainability accounting and reporting: fad or trend? Accounting, Auditing \& Accountability Journal, 23(7), 829-846. https://doi.org/10.1108/09513571011080144

Hasan, D. (2016). Testing and evaluation of the sustainability reports: A new challenge for the external auditing profession in light of the related review standards. The Accounting Intellect Journal, 20(2), 973-1024.

ISO26000: Sustainability as Standard. (2012).

Jomaah, A. H. (2009). The approach to modern audit and confirmation (1st ed.). Safa House for Publishing and Distribution, Amman, Jordan.

Kotayshat, A. (2010). Extent of availability of the necessary conditions for improvement of effictiveness of the audit committees formed in the Jordanian public shareholding companies. Master's thesis, Middle East University, Amman, Jordan.

Orij, R. (2010). Corporate social disclosure in the context of national cultures and stakeholder theory. Accounting, Auditing and Accountability Journal, 23(7), 868-89. https://doi.org/10.1108/09513571011080162

Seck, T. (2015). Sustainable development: An empirical illustration for Saudi Arabia. Journal of Developing Areas, 49(6), 517-529. https://doi.org/10.1353/jda.2015.0087

\section{Copyrights}

Copyright for this article is retained by the author(s), with first publication rights granted to the journal.

This is an open-access article distributed under the terms and conditions of the Creative Commons Attribution license (http://creativecommons.org/licenses/by/4.0/). 